\title{
Arabic translation and validation of the Nasal Obstruction Symptom Evaluation (NOSE) scale
}

\author{
Samy Elwany ${ }^{1 *}$ (D), Ahmed Atef ${ }^{2}$, Ahmed Soliman Ismail', Wael K. A. Hussein ${ }^{1}$, Ahmed Aly Ibrahim, \\ Mostafa Abdelnaby ${ }^{1}$, Mohamed Elgersh ${ }^{1}$ and Mohamed Elwany ${ }^{3}$
}

\begin{abstract}
Background: The Nasal Obstruction Symptom Evaluation (NOSE) scale has been developed and validated in English to overcome the controversies concerning other methods of evaluation of nasal obstruction. The scale is currently used worldwide and has been translated into several languages. The purpose of the present work was to translate the English (NOSE) scale into Arabic (A-NOSE) and to assess its validity and reliability in Arabic-speaking patients.

Results: The internal consistency and test-to-test reliability of the Arabic scale were statistically good. The differences between the scores of the patients and control subjects were statistically significant. Postoperative scores of the patients were significantly higher than preoperative scores. All participants completed the Arabic questionnaire easily and few of them required slight assistance.

Conclusions: The translated NOSE scale is easy to administer and can be a robust and usable outcome measure for patients with nasal obstruction. The translated scale is sensitive to changes in nasal airway patency and can be used in clinical practice and outcome research.
\end{abstract}

Keywords: NOSE scale, Nasal obstruction, Turbinates, Septoplasty, Septorhinoplasty

\section{Background}

Nasal obstruction is a very common symptom in rhinology practice. Evaluation of the symptom is usually based on the patient's complaint and the clinical examination. However, objective assessment of nasal obstruction frequently does not correlate adequately with the patient's subjective feelings.

The NOSE scale has been established and published in English in 2004 [1] to overcome the controversies concerning objective methods of evaluation of nasal obstruction [2]. Since then, the scale has been translated to several languages and has been increasingly used for assessing patients with nasal obstruction [2-6] [7-10].

\footnotetext{
* Correspondence: samy.elwany@alexmed.edu.eg; samyelwany@msn.com ${ }^{1}$ Department of Otolaryngology, Alexandria Faculty of Medicine, Alexandria, Egypt

Full list of author information is available at the end of the article
}

The NOSE scale is simple to administer and has been proved to be a reliable and well-validated instrument for assessing the impact of nasal obstruction on patients' quality of life [1].

The aim of the present work was to translate the NOSE scale into Arabic language and then to evaluate its validity in Arabic-speaking patients

\section{Methods}

The study prospectively included 172 patients with nasal obstruction and 76 asymptomatic control participants. The sample size was determined using standard calculations [11].

All participants had adequate reading and writing ability, and all of them signed informed consent. The research was approved by the Institutional Review Board of the hospital according to the Helsinki Declaration. 
Two independent medical translators translated the English NOSE scale (Fig. 1) into Arabic following the criteria of the Outcome Research Task Force [12]. The final combined translation was reviewed and approved by a third translator and the senior author. The final translation is uploaded as supplementary material (Additional file 1).

All participants answered the A-NOSE scale and visual analog (VAS) scale [1] during the first visit. One hundred twenty-one patients answered the A-NOSE questionnaire again after 3 days to evaluate test-to-test reliability.

The scores of the A-NOSE scale of all participants in the study group (172 patients) were correlated with their visual analog (VAS) scores for criterion validity analysis. VAS scores of each of the 5 items were determined by the patients, and the total VAS score was then correlated with A-NOSE scores.

Responsiveness analysis was performed postoperatively on 134 patients 3 months after surgery at the end of their follow-up period.

\section{Statistical analysis}

Statistical analysis was carried out using Graphpad Prism Statistical software ${ }^{\circ}$. The interal consistency of the translated scale was assessed by Cronbach's $\alpha$ coefficient. The minimum acceptable value was 0.7 .

Construct validity of the questionnaire was analyzed with a non-paired $t$ test. $P$ values less than 0.05 were considered significant.

Spearman's correlation coefficient was used to check test-to-test reliability both for total scores and individual scores of each item in the A-NOSE scale. The scores of the first and second questionnaires, 3 days apart, were used for the comparison. A correlation coefficient of 0.7 or more indicated good reliability.

Criterion validity was checked by correlating the ANOSE scale scores and VAS scores using Spearman's correlation coefficient. A correlation coefficient of 0.6 or more indicated good criterion validity.

The Cohen $D$ effect size was used to evaluate postoperative improvement. The paired $t$ test was used to evaluate the responsiveness of the questionnaire to changes in nasal patency after surgery. $P$ value $<0.05$ was considered statistically significant.

\section{Results}

The study included 172 patients with nasal obstruction due to septal deviation and/or turbinate hypertrophy. The control group consisted of 76 asymptomatic individuals with the patent nasal airway. The study and control groups were statistically matched for age and sex. The demographics of the patients and the related statistics of the study and control groups are shown in Table 1.

All participants answered translated questionnaire flawlessly or with minimal help. The average duration of answering the questionnaire was $7.5 \mathrm{~min}$.

Cronbach's $\alpha$ of the scale was 0.932 in the study group and 0.911 in the control group. When Cronbach's $\alpha$ was measured excluding one question at a time, the results were $0.901-0.936$ for the study group and 0.901-0.939 for the control group.

The scores of the study group were compared with the scores of the control group to evaluate the clinical (construct) validity of the scale. The mean score of the study cohort was $16.12 \pm 2.44$. The mean of the control group was $1.17 \pm 1.06$. The difference between the two means was statistically significant $(P<0.001)$.

The reproducibility of the test (test-to-test reliability) was assessed by correlating the scores of the first and second questionnaires of 121 patients who filled in the questionnaire twice. The correlation coefficient $(r)$ was 0.867 for the total score. The correlation coefficients $(r)$ for individual items (1-5) were 0.781, 0.923, 0.815, 0.991 , and 0.822 , respectively.

\begin{tabular}{|c|c|c|c|c|c|c|}
\hline \multicolumn{7}{|c|}{ Over the past 1 month. How much of a problem were the following conditions for you? } \\
\hline \multicolumn{7}{|c|}{ Please circle the most correct response } \\
\hline & & $\begin{array}{l}\text { Not a } \\
\text { problem }\end{array}$ & $\begin{array}{l}\text { Very mild } \\
\text { problem }\end{array}$ & \begin{tabular}{|l|}
$\begin{array}{l}\text { Moderate } \\
\text { problem }\end{array}$ \\
\end{tabular} & $\begin{array}{l}\text { Fairly bad } \\
\text { problem }\end{array}$ & $\begin{array}{l}\text { Severe } \\
\text { problem }\end{array}$ \\
\hline 1 & $\begin{array}{l}\text { Nasal congestion or } \\
\text { stuffiness }\end{array}$ & 0 & 1 & 2 & 3 & 4 \\
\hline 2 & $\begin{array}{l}\text { Nasal blockage or } \\
\text { obstruction }\end{array}$ & 0 & 1 & 2 & 3 & 4 \\
\hline 3 & $\begin{array}{l}\text { Trouble breathing } \\
\text { through the nose }\end{array}$ & 0 & 1 & 2 & 3 & 4 \\
\hline 4 & Trouble sleeping & 0 & 1 & 2 & 3 & 4 \\
\hline 5 & $\begin{array}{l}\text { Unable to get enough } \\
\text { aor through my nose } \\
\text { during exercise or } \\
\text { exertion }\end{array}$ & 0 & 1 & 2 & 3 & 4 \\
\hline
\end{tabular}

Fig. 1 The English version of the NOSE scale 
Table 1 Demographics and the related statistics of the study and control groups

\begin{tabular}{|c|c|c|c|c|c|}
\hline \multirow[t]{2}{*}{ Items } & \multirow[t]{2}{*}{ Statistical test } & \multirow{2}{*}{$\begin{array}{l}\text { Number of } \\
\text { participants }\end{array}$} & \multirow{2}{*}{$\begin{array}{l}\text { Mean age } \\
\text { (years) }\end{array}$} & \multicolumn{2}{|l|}{ Sex } \\
\hline & & & & Male & Female \\
\hline Internal consistency & Cronbach's a & $\begin{array}{l}\text { Study group (172) } \\
\text { Control group (76) }\end{array}$ & $\begin{array}{l}39 \pm 8.3(19-56) \\
40 \pm 8.22(20-54)\end{array}$ & $\begin{array}{l}136 \\
47\end{array}$ & $\begin{array}{l}36 \\
29\end{array}$ \\
\hline Construct validity & Non-paired $t$ test & $\begin{array}{l}\text { Study group (172) } \\
\text { Control group (76) }\end{array}$ & $\begin{array}{l}39 \pm 8.3(19-56) \\
40 \pm 8.22(20-54)\end{array}$ & $\begin{array}{l}136 \\
47\end{array}$ & $\begin{array}{l}36 \\
29\end{array}$ \\
\hline Reliability analysis & Spearman's test & Study group (121) & $39 \pm 5.9(19-55)$ & 99 & 22 \\
\hline Criterion validity & Spearman's test & Study group (172) & $\begin{array}{l}39 \pm 8.3(19-56) \\
40 \pm 8.22(20-54)\end{array}$ & $\begin{array}{l}136 \\
47\end{array}$ & $\begin{array}{l}36 \\
29\end{array}$ \\
\hline Effect size & Cohen's D & Study group (134) & $38 \pm 7.4(19-51)$ & 112 & 22 \\
\hline Responsiveness & Paired $t$ test & Study group (134) & $38 \pm 7.4(19-51)$ & 112 & 22 \\
\hline
\end{tabular}

The A-NOSE scores were correlated with VAS scores of the participants. The correlation coefficient $(r)$ was 0.765 confirming the criterion validity of the translated scale.

The mean postoperative scores of 134 patients $(6.1 \pm$ 2.09) were significantly lower than their mean preoperative score $(16.12 \pm 1.84)$, with a $P$ value $<0.001$. Cohen's $D$ effect size for the total A-NOSE score was 1.7584 , confirming adequate improvement after surgery.

\section{Discussion}

The NOSE scale was first published by Stewart et al. [1] as a validated tool to assess nasal obstruction and to overcome the limitations of objective tools. The NOSE scale gained popularity since it is a brief questionnaire with only five items. The scale allowed better assessment of nasal obstruction and facilitated the decision-making process and follow-up of the patients.

The NOSE scale was translated into several languages [3-6]. In this work, we translated the NOSE questionnaire into the Arabic language to make it available for the Arabic-speaking patients and then tested its validity, reliability, and responsiveness using standard statistical procedures [13].

All participants in the study understood and easily answered the 5 questions in less than $10 \mathrm{~min}$. Few participants needed assistance indicating that the A-NOSE scale is an easy-to-use outcome assessment tool that can be self-administered.

The results of Cronbach's test with $\alpha$ value of 0.932 in 172 patients and 0.911 in 76 control individuals confirmed good internal consistency of the scale and are also close to those reported previously in other languages [2].

Patients with septal deviation and/or turbinate hypertrophy scored significantly higher values of A-NOSE than normal controls. This shows the robust construct validity of the questionnaire and confirms its sensitivity as a subjective tool for the assessment of nasal obstruction.
Reproducibility of the A-NOSE was also good, with Spearman's coefficient value of 0.867 for the total score. This agrees with the findings of other studies and confirms the test-to-test reliability of the scale over time.

The study showed also a positive correlation between A-NOSE and VAS scores. This agrees with the study of Karahatay et al. [2] and confirms the clinical validity of the A-NOSE scale.

One hundred thirty-four patients completed A-NOSE questionnaire 3 months after surgery. The preoperative scores were significantly higher than the postoperative scores. Substantial postoperative improvement was also shown by analysis of Cohen's $D$ effect size test results. This is in agreement with previous studies and shows that A-NOSE is a valid and reliable tool to assess the changes in the severity of nasal obstruction and can be useful in following up the patients after treatment or surgery.

\section{Conclusions}

Analysis of the results confirms the validity and suitability of the A-NOSE scale for the assessment of nasal obstruction in Arabic-speaking adult patients. The questionnaire was self-administered without difficulty in the office in few minutes after a brief explanation. The present study endorses the use of the translated ANOSE scale as a trustworthy self-administered subjective tool for the assessment of nasal obstruction as well as an outcome research tool.

\section{Abbreviations}

NOSE scale: Nasal Obstruction Symptom Evaluation scale; A-NOSE scale: Arabic Nasal Obstruction Symptom Evaluation scale; VAS: Visual analog score

\section{Supplementary Information}

The online version contains supplementary material available at https://doi. org/10.1186/s43163-021-00156-z.

Additional file 1. Arabic translation of the NOSE scale (A-NOSE). A figure showing the validated Arabic translation of the NOSE. 


\section{Acknowledgements}

Not applicable.

\section{Authors' contributions}

SE designed and supervised the work and revised the final manuscript. AA contributed to the analysis of the data and writing the draft. Al contributed to the collection of the data and revising the manuscript. WK contributed to the collection of the data and revising the results. AAI contributed to the collection of data. MA contributed to the collection of the data. MY contributed to the collection of the data. ME performed the statistics of the work. The authors have read and approved the manuscript.

\section{Funding}

None.

\section{Availability of data and materials}

The datasets used and/or analyzed during the current study are available from the corresponding author on reasonable request.

\section{Declarations}

\section{Ethics approval and consent to participate}

This study was approved by the ethics committee of the hospital (Alexandria University), and all participants signed written informed consents. The reference number is not applicable.

\section{Consent for publication}

Not applicable

\section{Competing interests}

Prof Ahmed Atef is a co-author of this study and the Editor-in-Chief of the journal. He declares a competing interest for this submission. He has not handled this manuscript. The rest of the authors have no conflict of interest to declare.

\section{Author details}

'Department of Otolaryngology, Alexandria Faculty of Medicine, Alexandria, Egypt. ${ }^{2}$ Department of Otolaryngology, Cairo Faculty of Medicine, Cairo, Egypt. ${ }^{3}$ LHI USA, Altamonte Springs, Florida, USA.

Received: 8 June 2021 Accepted: 20 August 2021

Published online: 17 September 2021

\section{References}

1. Stewart MG, Witsell DL, Smith TL, Weaver EM, Yueh B, Hannley MT (2004) Development and validation of the Nasal Obstruction Symptom Evaluation (NOSE) scale. Otolaryngol Head Neck Surg 130(2):157-163. https://doi.org/1 0.1016/j.otohns.2003.09.016

2. Karahatay S, Taşli H, Karakoç Ö, Aydin Ü, Türker T (2018) Reliability and validity of the Turkish nose obstruction symptom evaluation (NOSE) scale. Turk J Med Sci 48(2):212-216. https://doi.org/10.3906/sag-1509-81

3. Larrosa F, Roura J, Dura MJ, Guirao M, Alberti A, Alobid I (2015) Adaptation and validation of the Spanish version of the Nasal Obstruction Symptom Evaluation (NOSE) Scale. Rhinology 53(2):176-180. https://doi.org/10.4193/ Rhin 14.137

4. Mozzanica F, Urbani E, Atac M, Scottà G, Luciano K, Bulgheroni C, de Cristofaro V, Gera R, Schindler A, Ottaviani F (2013) Reliability and validity of the Italian nose obstruction symptom evaluation (I-NOSE) scale. Eur Arch Otorhinolaryngol 270(12):3087-3094. https://doi.org/10.1007/s00405-013-242 6-z

5. Bezerra TFP, Padua FGM, Pilan RRM, Stewart MG, Voegels RL (2011) Crosscultural adaptation and validation of a quality of life questionnaire: the Nasal Obstruction Symptom Evaluation questionnaire. Rhinology 49(2):227231. https://doi.org/10.4193/Rhino10.019

6. Marro M, Mondina M, Stoll D, de Gabory L (2011) French validation of the NOSE and RhinoQOL questionnaires in the management of nasal obstruction. Otolaryngol Head Neck Surg 144(6):988-993. https://doi.org/1 $0.1177 / 0194599811400686$

7. Spiekermann C, Savvas E, Rudack C, Stenner M (2018) Adaption and validation of the nasal obstruction symptom evaluation scale in German language (D-NOSE). Health Qual Life Outcomes 16(1):172. https://doi.org/1 $0.1186 / s 12955-018-1004-x$

8. Lachanas VA, Tsiouvaka S, Tsea M, Hajiioannou JK, Skoulakis CE (2014) Validation of the nasal obstruction symptom evaluation (NOSE) scale for Greek patients. Otolaryngol Head Neck Surg 151(5):819-823. https://doi. org/10.1177/0194599814544631

9. Dong D, Zhao Y, Stewart MG, Sun L, Cheng H, Wang J, Li W (2014) Development of the Chinese nasal obstruction symptom evaluation (NOSE) questionnaire. Chin J Otorhinolaryngol Head Neck Surgery 49(1):20-26

10. van Zijl FWWJ, Timman R, Datema FR (2017) Adaptation and validation of the Dutch version of the nasal obstruction symptom evaluation (NOSE) scale. Eur Arch Otorhinolaryngol 274(6):2469-2476. https://doi.org/10.1007/ s00405-017-4486-y

11. Charan J, Biswas T (2013) How to calculate sample size for different study designs in medical research? Indian J Psychol Med 35(2):121-126. https:// doi.org/10.4103/0253-7176.116232

12. Wild D, Grove A, Martin M, Eremenco S, McElroy S, Verjee-Lorenz A, Erikson $P$ (2005) Principles of good practice for the translation and cultural adaptation process for patient-reported outcomes (PRO) measures: report of the ISPOR Task Force for Translation and Cultural Adaptation. Value Health 8(2):94-104. https://doi.org/10.1111/j.1524-4733.2005.04054.x

13. Beaton DE, Bombardier C, Guillemin F, Ferraz MB (2000) Guidelines for the process of cross-cultural adaptation of self-report measures. Spine 25(24): 3186-3191. https://doi.org/10.1097/00007632-200012150-00014

\section{Publisher's Note}

Springer Nature remains neutral with regard to jurisdictional claims in published maps and institutional affiliations.

\section{Submit your manuscript to a SpringerOpen ${ }^{\circ}$ journal and benefit from:}

- Convenient online submission

- Rigorous peer review

- Open access: articles freely available online

- High visibility within the field

- Retaining the copyright to your article

Submit your next manuscript at $\boldsymbol{\nabla}$ springeropen.com 